\title{
O Banco Nacional do Desenvolvimento Econômico
}

\author{
Sebastião de Sant'Anna E Silva
}

\begin{abstract}
A
PESAR dos cinco anos já decorridos desde sua criação, ainda se verifica, mesmo nos meios bem informados sôbre assuntos econômicos e financeiros, pouco conhecimento a respeito da exata natureza e das reais finalidades do Banco Nacional do Desenvolvimento Econômico.

A origem do Banco é encontrada no artigo $3 .^{\circ}$ da Lei n. ${ }^{\circ} 1.474$, de 26 de novembro de 1951, onde foram criados dois adicionais ao impôsto de renda: um de $15 \%$ sôbre o montante do impôsto devido pelas pessoas físicas, quando excedente a $\operatorname{Cr} \$ 10.000,00$, e outro de $3 \%$ sôbre as reservas e lucros em suspenso ou não distribuídos, em poder de pessoas jurídicas. Determinou ainda o mesmo diploma legal que o produto da cobrança dos adicionais constituísse um fundo especial com personalidade contábil para ser aplicado na execução do programa de reaparelhamento de portos e ferrovias, aumento da capacidade de armazenamento, frigoríficos e matadouros, elevação d potencial de energia elétrica e desenvolvimento de indústrias básicas e agricultura.
\end{abstract}

Ao estabelecer que as importâncias provenientes da cobrança dos referidos adicionais fôssem, no decurso do sexto exercício e após o respectivo recolhimento, restituídas aos contribuintes, com uma bonificação, em títulos da dívida pública, retirou a lei o caráter de impôsto aos adicionais em causa, configurando-os como uma modalidade de empréstimo compulsório.

Na exposição de motivos de 6 de fevereiro de 1952, na qual justificou a proposta de criação do Banco Nacional do Desenvolvimento Econômico, historiou o Ministro HoRÁcio LAFER, então titular da pasta da Fazenda, os entendimentos realizados com altas autoridades financeiras dos Estados Unidos da América, visando à obtenção dos indispensáveis recursos, em divisas, necessários ao Brasil para adquirir equipamentos e maquinismos destinados à obra de recuperação econômica do país. Como conseqüência dêsses entendimentos foram constituídos um "grupo misto" e uma "comissão mista", ambos integrados por técnicos brasileiros e americanos. O "grupo misto" teve como finalidade estudar e sugerir providências de efeito imediato, capazes de assegurar o abastecimento de matérias-primas indispensáveis ao funcionamento do parque industrial brasileiro. A "comissão mista", por sua vez, foi organizada a fim de equacionar os problemas fundamentais do país e recomendar medidas de longo alcance visando ao reaparelhamento do Brasil nos 
setores de maior importância, tais como transportes, energia e indústrias básicas.

Os estudos iniciais procedidos pela Comissão Mista Brasil-Estados Uni.. dos estimaram em um mínimo de 20 bilhões de cruzeiros o custo da execução de um programa de recuperação econômica do Brasil. A metade dessa importância, ou seja o equivalente a 500 milhões de dólares, ao câmbio oficial, seria levantada através de uma operação de crédito no exterior e destinarse-ia à compra de equipamentos importados e ao pagamento de serviços estrangeiros indispensáveis. Os 10 bilhões de cruzeiros restantes, destinados a atender a despesas com o pagamento de materiais produzidos no país e serviços aqui executados, deveriam ser obtidos através de um processo de transferência, para o setor público da economia nacional, de poupanças disponíveis no setor privado.

Em lugar de lançar mão da tributação pura e simples para a consecução dessa transferência preferiu o Govêrno usar o mecanismo do empréstimo, através do qual se garantisse a futura restituição ao setor privado da economia da parcela de poupança transferida ao Govêrno. Dadas as dificuldades de utilização do empréstimo voluntário em uma conjuntura inflacionária, foi preferido o sistema do empréstimo compulsório. O mecanismo utilizado para a consecução dos fundos do empréstimo: criação de adicionais ao impôsto de renda, garantiu que o levantamento dos recursos se fizesse, de preferência, nos grupos da população de mais elevado poder de compra e de maior propensão para poupar.

Sem embargo das críticas feitas à escolha do processo do empréstimo forçado, pode-se afirmar ter o sistema adotado constituído um processo são de financiamento dos projetos de reaparelhamento econômico do país. A transferência de poupança do setor privado para o setor público, conseguida através do empréstimo compulsório, eliminou os efeitos inflacionários dos investimentos programados, evitando que se tornasse ainda mais aguda a concorrência entre o Govêrno e as emprêsas privadas na disputa de fatôres de produção escassos.

A obtenção dos recursos em moeda estrangeira foi assegurada pelo acôrdo financeiro firmado em Washington, em 14 de setembro de 1951, entre - Ministro da Fazenda do Brasil, de um lado, e de outro o Secretário do Tesouro Americano, o Secretário-Assistente do Departamento de Estado e os Presidentes-executivos do Banco de Exportação e Importação e do Banco Internacional de Reconstrução e Desenvolvimento. Pelo artigo $10^{\circ}$ da Lei n. ${ }^{\circ}$ 1.518, de 24 de dezembro de 1951, foi o Poder Executivo autorizado a contratar ou a dar a garantia do Tesouro Nacional para a obtenção, no exterior, de créditos até o limite de 500 milhões de dólares, para o fim especial de financiar o programa de reaparelhamento de portos, sistemas de transportes, aumento da capacidade de armazenamento, frigoríficos e matadouros, elevação do potencial de energia elétrica e desenvolvimento de indústrias básicas e agricultura.

Uma vez garantidos os recursos em cruzeiros e em moeda estrangeira para execução do programa de reaparelhamento econômico, tornou-se neces- 
sária a expedição de normas legais complementares, nas quais fôssem estabelecidas a qualidade, o tipo, os juros, as amortizações e o resgate dos títulos da dívida pública correspondentes ao empréstimo compulsório já autorizado e fôsse assegurado, através da criação de um fundo especial, o serviço de juros, amortização e resgate dos mesmos títulos. Julgou-se também aconselhável ampliar a fonte de recursos em moeda nacional para financiamento dos projetos de reaparelhamento econômico, mediante a captação de fundos provenientes de poderosas concentrações financeiras. Finalmente, tornou-se indispensável a criação de um organismo governamental capaz de atuar como agente do Govêrno Brasileiro nas operações monetárias ligadas ao reaparelhamento econômico, administrar os fundos correspondentes e controlar sua aplicação.

Essas normas legais complementares foram compendiadas na Lei número 1.628, de 20 de junho de 1952, que dispôs sôbre a restituição dos adicionais criados pelo artigo $3 .^{\circ}$ da Lei n. ${ }^{\circ} 1.474$, de 26 de novembro de 1951 e fixou a respectiva bonificação; autorizou a emissão de obrigações da Dívida Pública Federal e criou o Banco Nacional do Desenvolvimento Econômico.

O Banco Nacional do Desenvolvimento Econômico foi dotado pela Lei n. ${ }^{\circ} 1.628$ de autonomia administrativa e personalidade jurídica própria, gozando, como serviço público federal, das vantagens e regalias respectivas. O Banco foi autorizado a exercer tôdas as atividades bancárias, na forma da legislação em vigor, sendo todavia limitada pela lei a sua faculdade de receber depósitos. Foi ainda estabelecido de forma taxativa que o Banco só poderia efetuar empréstimos ou financiamentos com os objetivos de reaparelhamento de portos e ferrovias, aumento da capacidade de armazenamento, frigoríficos e matadouros, elevação do potencial de energia elétrica e desenvolvimento de indústrias básicas e da agricultura.

Ao definir as atribuições do Banco, a Lei n. ${ }^{\circ} 1.628$ o autorizou a receber os adicionais do impôsto de renda bem como os tributos criados para execução do programa de reaparelhamento e fomento econômico, assim como a movimentar os créditos obtidos no exterior para o financiamento do mesmo programa. Ao Banco foi também atribuída a responsabilidade de satisfazer os compromissos decorrentes do serviço de juros, amortizações e resgate dos encargos assumidos no país e no exterior em virtude da execução de programas de reaparelhamento e fomento, inclusive no tocante às obrigações governamentais resultantes do empréstimo compulsório autorizado. Finalmente, foi conferida ao Banco a atribuição de controlar e fiscalizar a aplicação dos recursos de qualquer procedência destinados a obras, serviços ou investimentos incluídos no programa de reaparelhamento e fomento da economia nacional, bem como a contratar, no exterior, por si ou como agente de governos, entidades autárquicas, sociedades de economia mista e organizações privadas, a abertura de créditos destinados à execução do mesmo programa.

Para o eficiente desempenho de seus amplos e complexos encargos, foi - Banco Nacional do Desenvolvimento Econômico dotado da mais ampla autonomia administrativa e financeira, embora tenha sido incluído na jurisdição do Ministro da Fazenda com a obrigação de prestar suas contas ao 
Tribunal de Contas. Como órgãos encarregados de sua administração foram criados uma Diretoria e um Conselho de Administração. À Diretoria, integrada por quatro membros, número êste elevado para 6 em 1956, foi atribuída a direção executiva do Banco bem como o poder de decisão sôbre as suas operações. Ao Conselho de Administração, composto de sete membros, conferiu a lei os poderes de estabelecer a organização interna do Banco, orientar as suas operações traçando as normas a que devam obedecer, criar cargos e funções fixando a correspondente remuneração, examinar e julgar os balancetes e balanços e dar parecer sôbre a prestação anual das contas da autarquia.

O Banco Nacional do Desenvolvimento Econômico foi instalado em 1952 e em novembro dêsse ano realizou a sua primeira operação, consistente na concessão de um empréstimo no valor de $\operatorname{Cr} \$ 1$ 181.000.000,00 à Estrada de Ferro Central do Brasil para o reaparelhamento da ferrovia, com base no Projeto n. ${ }^{\circ} 3$ da Comissão Mista Brasil-Estados Unidos. Na mesma data e para execução do mesmo projeto deu o Banco a sua garantia, em nome do Tesouro Nacional, para a concessão, pelo Banco Internacional de Reconstrução e Desenvolvimento, do empréstimo de 12.500 .000 dólares norteamericanos à Estrada de Ferro Central do Brasil.

A partir de novembro de 1952 e até 30 de setembro do corrente ano assinou o Banco Nacional do Desenvolvimento Econômico 82 contratos de financiamento, no valor total de $\operatorname{Cr} \$ 14.046 .507 .445,70$ e deu a sua garantia, em nome do Tesouro Nacional, para a obtenção de financiamentos, no valor total de 36.600.000 dólares americanos, concedidos pelo Banco de Exportação e Importação de Washington ou pelo Banco Internacional de Reconstrução e Desenvolvimento. Dos financiamentos concedidos em cruzeiros haviam sido utilizados, até 30-9-1957, pelos diversos mutuários, Crs 8.679.041.515,20, e dos financiamentos em dólares, garantidos pelo Banco, já tinham sido sacados, até a mesma data, US\$ $34,587,131.80$. Outrossim, desde o início de suas operações até o fim do mês de setembro concedeu o Banco avais no valor total de US\$ $69,776,308.44$ e DM 26.555.139,13 para obtenção de financiamentos no exterior, a curto e a médio prazo, por emprêsas particulares ou governamentais.

Se analisarmos os financiamentos concedidos pelo Banco Nacional do Desenvolvimento Econômico, até 30-9-1957, a fim de discriminá-los pelos diversos setores beneficiados, encontramos a seguinte distribuição:

Moeda Nacional

Cr\$

Ferrovias. . . . .................

Frigoríficos e Matadouros.

Indústrias Básicas.

Energia Elétrica.

Rodovias.

Portos, Rios e Canais.................

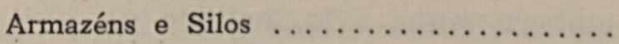

Transportes Marítimos.
$6.423 .213 .569,80$

$184.000 .000,00$

$1.538 .044 .688,00$

$5.488 .725 .187,90$

$13.240 .000,00$

$267.956 .000,00$

$31.328 .000,00$
Moeda Estrangeira

US\$

$33,600,000.00$

$3,000,000.00$ 
Além das operações de empréstimos e financiamentos para o reaparelhamento e o fomento da economia nacional, ao Banco Nacional do Desenvolvimento Econômico têm sido atribuídos, por leis especiais, diversos outroz encargos relacionados com a execução do mesmo programa. Foi-lhe entregue, por exemplo, o depósito e administração das taxas de melhoramentos e de renovação patrimonial das ferrovias pertencentes à União ou por ela arrendadas. Cabe igualmente ao Banco receber em depósito e administrar o Fundo de Pavimentação de Rodovias, o Fundo Nacional de Eletrificação e o Fundo Portuário Nacional, criados para a execução de programas especiais, relacionados com setores específicos da economia nacional. Realiza ainda o Banco outras operações, tais como a compra, no país ou no exterior, de equipamentos para seus mutuários, bem como a subscrição, em seu próprio nome ou do Tesouro Nacional, de ações ou obrigações de emprêsas privadas ou sociedades de economia mista.

Pela Lei n. ${ }^{\circ}$ 2.973, de 26 de novembro de 1956, foi prorrogada a vigência das medidas de ordem financeira relacionadas com a execução do Plano de Desenvolvimento Econômico. Essa nova lei objetivou, em primeiro lugar, a prorrogação, pelo prazo de 10 anos, do empréstimo compulsório ao Banco Nacional do Desenvolvimento Econômico, cobrado sob a forma de adicionais ao impôsto de renda e cuja vigência deveria terminar em 31 de dezembro de 1956. Não se limitou porém a nova legislação à prorrogação pura e simples dos adicionais do impôsto de renda, mas introduziu profundas alterações no próprio sistema de captação de recursos para o Plano de Desenvolvimento Econômico, alterando ainda a organização e as normas de ação do Banco Nacional do Desenvolvimento Econômico. O adicional ao impôsto de renda passou a ser exigido com base em uma alíquota, ligeiramente progressiva, das pessoas físicas sujeitas a pagamento de tributo superior a 20.000 cruzeiros, mantendo-se o adicional de $15 \%$ sôbre o impôsto devido pelas pessoas jurídicas e elevando-se a $4 \%$ o adicional calculado sôbre as reservas e lucros em suspenso ou não distribuídos em poder das emprêsas. Disciplinou ainda a nova lei, de forma detalhada, a emissão e o resgate das Obrigações do Reaparelhamento Econômico e baixou normas disciplinadoras das operações do Banco, além de outras relativas à administração do estabelecimento e contrôle financeiro de suas atividades.

Os cinco anos de funcionamento e de operação do Banco Nacional do Desenvolvimento Econômico já permitem considerá-lo uma iniciativa plenamente vitoriosa, da qual têm decorrido indiscutíveis e palpáveis benefícios para a economia nacional. Antes do Banco, outras iniciativas governamentais tinham sido levadas a efeito, notadamente através do Plano Salte, visando à execução de um programa de investimentos capazes de acelerar o desenvolvimento econômico do país. Tais iniciativas encontraram todavia dois grandes obstáculos que comprometeram os seus resultados. Um dêles foi a falta de um esquema adequado para o financiamento dos investimentos programados, do que resultou o respectivo custeio através de dotações orçamentárias com o conseqüente agravamento do đeficit das contas públicas. O segundo residiu na falta de um organismo convenientemente aparelhado para a 
administração do programa, contrôle de sua execução e fiscalização dos recursos a êle destinados.

A experiência dos insucessos anteriores determinou a adoção de cuidados especiais na elaboração do esquema de financiamento do Plano de Reaparelhamento e Fomento da Economia Nacional, notadamente visando evitar que dêsse financiamento pudessem resultar consequiências indesejáveis, agravadoras da pressão inflacionária cuja intensidade se fazia sentir. O único meio de assegurar um financiamento são dos investimentos projetados seria conseguir a transferência, para o setor público, de poupanças disponíveis no setor privado. Teria sido sem dúvida desejável que tal transferência não tivesse caráter compulsório, efetivando-se mediante um empréstimo público de natureza voluntária. Em 1956, todavia, a conjuntura inflacionária já se fazia sentir com tôda intensidade e criava, como ainda cria nos dias de hoje, óbices pràticamente intransponíveis à colocação, no mercado de títulos, de apólices e obrigações do Tesouro. Impôs-se portanto a necessidade da obtenção dessa transferência mediante um processo compulsório, vendo-se o Govêrno colocado diante da alternativa: impôsto ou empréstimo forçado, como único sistema financeiramente são de captação de recursos para o financiamento dos projetos de reaparelhamento econômico.

Preferiu-se o empréstimo ao impôsto por motivos diversos, inclusive de natureza psicológica, consistente na esperança de uma aceitação mais fácil pelo Parlamento e pelo público do esquema proposto. A solução do empréstimo oferecia, ainda, a grande vantagem de criar para o organismo responsável pela aplicação dos recursos assim obtidos, a responsabilidade de segura e criteriosa aplicação, capaz de criar os meios necessários para o pagamento dos juros e amortizações correspondentes. Evitava-se por êsse meio o critério assistencial tão comum na aplicação dos dinheiros públicos e dotações orçamentárias, pois a utilização dos recursos resultantes do empréstimo compulsório em empréstimos de favor ou empreendimentos duvidosos sem rentabilidade assegurada acarretaria, fatalmente, o insucesso de todo o sistema e a insolvência do órgão responsável pela execução do esquema financeiro.

A escolha de adicionais ao impôsto de renda como fonte principal para captação dos recursos teve o objetivo de evitar a imposição de um novo sacrifício pecuniário sôbre as classes menos favorecidas e fazer com que o ônus recaísse de preferência sôbre as classes com propensão para poupar ou seja sôbre os titulares de rendimentos acima de certo nível. A incidência dos adicionais sôbre as pessoas jurídicas, inclusive sôbre suas reservas, lucros suspensos e não distribuídos, teve a finalidade de transferir para o Tesouro uma parte da poupança retida nas emprêsas privadas a fim de possibilitar reinvestimentos através do autofinanciamento. Essa transferência justificava-se plenamente, uma vez que os recursos captados através dos adicionais do impôsto de renda formariam um fundo destinado a financiar projetos e empreendimentcs privados ao lado de investimentos e projetos governamentais, desde que se enquadrassem uns e outros nos objetivos do programa de reapa. relhamento econômico e fomento da economia nacional. Finalmente, a transferência compulsória para o fundo de reaparelhamento econômico de uma 
parte das reservas das emprêsas de seguro privado e capitalização e das instituições de previdência bem como dos depósitos das caixas econômicas federais objetivou a aplicação parcial dessas reservas e depósitos em investimentos essenciais ao desenvolvimento econômico do país, evitando-se sua total canalização para setores menos prioritários, tais como as aplicações imobiliárias.

Caracterizou-se portanto o esquema de financiamento do programa de reaparelhamento econômico pelo seu caráter são e pela ausência de efeitos inflacionários. Não implicou êle em qualquer despesa orçamentária adicional nem agravou a posição do Tesouro no Banco do Brasil, não resultando, portanto, dessa operação, qualquer pressão tendente a aumentar os meios de pagamento. Ao contrário, como até o exercício de 1956 o produto dos adicio. nais do impôsto de renda era recolhido ao Banco Nacional do Desenvolvimento Econômico através do Tesouro Nacional, dispôs êste da massa de recursos ccrrespondente a fim de minorar seus desequilíbrios temporários de caixa.

A criação do Banco Nacional do Desenvolvimento Econômico constituiu também uma garantia de êxito do programa de reaparelhamento e de fomento da economia nacional. Ao organismo instituído para atuar como agente do Govêrno Brasileiro nas operações monetárias ligadas ao reaparelhamento eco. nômico deu-se ampla autonomia administrativa e técnica. Livre das peias que entorpecem e dificultam a ação dos órgãos da administração direta, dispõe o Banco de ampla flexibilidade no manuseio e aplicação dos recursos por êle administrados. A sua direção colegiada, com duração do mandato fixada em lei, salvo no caso do Presidente do Banco, assegura continuidade administrativa bem como alto grau de isenção e independência nas decisões tomadas, permitindo o afastamento das pressões político-partidárias e dos grupos econômicos. Finalmente, a autonomia assegurada ao Banco no recrutamento de seu pessoal e na fixação dos respectivos vencimentos e vantagens permitiu-lhe a formação de um quadro de alto nível profissional e técnico.

O problema crucial dos países subdesenvolvidos como o Brasil é o da formação do volume de capital necessário para o aumento do produto nacional e melhoria do padrão de vida da população. Essa formação de capital é todavia lenta em decorrência do pequeno volume de poupança resultante da insuficiência do produto nacional. Trata-se portanto de um círculo vicioso cujo rompimento é essencial para acelerar o processo do desenvolvimento econômico.

A filosofia que presidiu a criação do Banco Nacional do Desenvolvi. mento Econômico foi a crença de ser possível ao Estado, através de uma intervenção adequada, obter um maior volume de poupança global e alterar a composição dos investimentos. O Banco exerce com êsse objetivo uma ação tríplice. Impondo-se à confiança dos capitalistas estrangeiros e organizações financeiras internacionais, promove uma ação efetiva no sentido da atração de maior volume de capitais externos, a serem aqui aplicados sob a forma de empréstimos ou de inversões diretas. O capital nacional, insuficiente para a promoção do desenvolvimento econômico na escala desejada, é assim suple- 
mentado por um afluxo de capitais estrangeiros, os quais encontram no Banco Nacional do Desenvolvimento Econômico amparo e garantia para sua aplicação.

A ação do Banco visa, ainda, obter um maior volume de poupança interna. Os adicionais do impôsto de renda, base fundamental dos recursos por êle mobilizados, resultam em parte da compressão forçada do poder de compra de grupos sociais com forte tendência para aplicação de uma parcela de sua renda em consumos não essenciais. Traduz-se portanto essa ação em uma transformação de gastos potenciais de consumo em poupança destinada ao financiamento de investimentos considerados como prioritários e essen. ciais.

A terceira forma de ação do Banco consiste em disciplinar o investimento global, imprimindo-lhe uma escala de prioridades estabelecida de acôrdo com as exigências do desenvolvimento econômico do país. Parte da poupança privada que seria aplicada exclusivamente visando o mais elevado benefício possível para o seu titular, é aplicada, através do Banco, no finan. ciamento de investimentos privados e governamentais que se destinam à eliminação de pontos de estrangulamento da economia nacional e à execução de projetos básicos e essenciais ao nosso desenvolvimento econômico.

Outro aspecto relevante da ação exercida pelo Banco Nacional do Desenvolvimento Econômico é o 'seu caráter educativo. Já se afirmou, com razão, que o Banco não financia pessoa ou entidades e sim projetos. Requisito fundamental e essencial para a obtenção de um empréstimo é a apresentação de projeto detalhado, através do qual seja possível caracterizar o empreendimento como tècnicamente correto, econômicamente aconselhável e financeiramente são. O Banco não distingue, ao examinar os projetos submetidos ao seu estudo, os oriundos de instituições governamentais ou semigovernamen- tais dos apresentados por emprêsas privadas, sejam estas nacionais ou estrangeiras. O critério adotado consiste no enquadramento do projeto entre os que, pela lei de sua criação, está o Banco autorizado a financiar e, após êsse enquadramento, a verificação do grau de prioridade que se lhe deverá atribuir, sem se levar em consideração a natureza pública ou privada do postulante do empréstimo.

Em conseqüência do critério adotado pelo Banco na realização de suas operações vão os admin:stradores de emprêsas, sejam estas públicas ou priva. das, adquirindo o hábito, altamente benéfico, de projetar e programar a longo prazo os seus investimentos, analisar com cuidado os custos de produção, as condições do mercado, as perspectivas de rentabilidade e outros fatôres. Procura o Banco convencer os empresários de que a concessão de crédito não é um favor ou um instrumento assistencial, mas uma alavanca poderosa do progresso técnico e do desenvolvimento econômico.

Em suas relações com as emprêsas governamentais, quer estejam estas incluídas no campo da administração direta, quer se trate de autarquias ou sociedades de economia mista, o Banco procura fazer com que tôdas elas reconheçam o seu caráter de emprêsa e adquiram consciência de sua responsa- 
bilidade na administração de uma determinada parcela de capital, cuja remuneração deverá ser assegurada através de métodos e processos de trabalho adequados a atividades de caráter industrial.

Ainda é cedo, não há dúvida, para um julgamento final e definitivo da ação do Banco Nacional do Desenvolvimento Econômico. A sua criação veio, todavia, atender a um imperativo de nosso desenvolvimento econômico, pois em todos os setores da economia nacional fazia-se sentir a necessidade de uma ação ordenada e planejada do Estado no sentido de acelerar êsse desenvolvimento. $\mathrm{E}$ os resultados benéficos de suas operações foram reconhecidos pelo Parlamento Nacional quando êste último, por expressiva maioria, decidiu prorrogar por mais 10 anos o levantamento dos recursos financeiros necessários à garantia da execução do Plano de Reaparelhamento e de Fomento da Economia Nacional. 